\title{
Aplicação foliar de manganês em soja transgênica tolerante ao glyphosate
}

\author{
Foliar application of manganese in transgenic soybean tolerant to glyphosate
}

\section{Claudir José Basso $^{\mathrm{I} *}$ Antônio Luis Santi ${ }^{\mathrm{I}}$ Fabiane Pinto Lamego ${ }^{\mathrm{I}}$ Eduardo Girotto ${ }^{\mathrm{II}}$}

\section{RESUMO}

O amarelecimento da soja Roundup Ready após aplicação do glyphosate pode estar associado à deficiência momentânea de manganês. Por isso, com a hipótese de que soja tolerante ao glyphosate necessitaria de uma adição suplementar de manganês, o objetivo deste trabalho foi avaliar diferentes manejos na aplicação foliar de manganês sobre alguns parâmetros da soja. Foram desenvolvidos dois experimentos, um no município de Taquaruçú do Sul e outro em Boa Vista das Missões, RS, no ano agrícola 2009/2010. Foram testados os seguintes tratamentos: 1) sem aplicação de glyphosate, com controle manual das plantas daninhas e sem aplicação foliar de manganês (testemunha); 2) sem aplicação de glyphosate, com controle manual das plantas daninhas $e$ uma aplicação foliar de manganês sete dias após esse controle manual das plantas daninhas; 3) com aplicação de glyphosate e sem aplicação foliar de manganês; 4) aplicação de glyphosate em mistura com manganês; 5) aplicação de glyphosate mais uma aplicação foliar de manganês sete dias após aplicação do glyphosate; 6) aplicação de glyphosate mais aplicação foliar de manganês parcelada em duas épocas, aos 7 e 14 dias após aplicação do glyphosate; 7) aplicação de glyphosate e uma aplicação foliar de manganês aos 14 dias após aplicação de glyphosate. A aplicação de glyphosate foi realizada no estádio V5 da soja, na dose de $720 \mathrm{~g} \mathrm{~L}^{-1}$ e.a, enquanto a dose de Mn utilizada foi 2,0L $\mathrm{ha}^{-1}$ de uma formulação contendo $14 \%$ $(\mathrm{m} / \mathrm{v})$ de manganês solúvel. Não houve diferença significativa entre os tratamentos para as variáveis estatura de plantas $e$ altura de inserção da primeira vagem. A aplicação de glyphosate não afetou a absorção e o teor foliar de manganês e nitrogênio na cultura da soja. Mesmo com aumento no teor foliar de manganês com a suplementação de manganês, não houve incremento na produtividade da soja. Isso mostra que em solos com teores de Mn acima do suficiente a aplicação do herbicida glifosato não requer a suplementação foliar de

\begin{abstract}
manganês em soja geneticamente modificada tolerante a esse herbicida.
\end{abstract}

Palavras-chave: estatura de planta, concentração foliar manganês, produtividade da soja.

\section{ABSTRACT}

The yellowing of Roundup Ready soybean after glyphosate application, can be associated to a momentary manganese deficiency. Because of that, with the hypothesis that glyphosate tolerant soybean would need supplementary addition of manganese, the objective of this research was to evaluate different managements in the foliar application of manganese in some soybean parameters. It was developed two experiments, one at Taquaruçú do Sul and other at Boa Vista das Missões, RS in the year of 2009/2010. It was tested the following treatments: 1) without glyphosate application with manual weed control and without manganese foliar application (untreated check); 2) without glyphosate application with manual weed control and one manganese foliar application at 7 days after this manual weed control; 3) with glyphosate application and without manganese foliar application; 4) glyphosate application in mixture with manganese; 5) glyphosate application added of one manganese foliar application at 7 days after glyphosate application; 6) glyphosate application added of manganese foliar application split in two times, at 7 and 14 days after glyphosate application; 7) glyphosate application and one of manganese foliar application at 14 days after glyphosate application. The glyphosate application was realized in the V5 soybean stage, using $720 \mathrm{~g} \mathrm{~L}^{-1}$ i.e, while the used dose of Mn was $2.0 \mathrm{~L} \mathrm{ha-1}$ of a formulation with $14 \%(\mathrm{~m} / \mathrm{v})$ of $\mathrm{Mn}$. There were no significant difference among the treatments to plant height and height insertion of the first legume. The glyphosate application did not affect the absorption and the foliar amount of manganese

'Universidade Federal Santa Maria (UFSM), 98400-000, Frederico Westphalen, RS, Brasil. E-mail: claudirbasso@gmail.com. *Autor para correspondência.

"UFSM, Santa Maria, RS, Brasil. 
and nitrogen in soybean crop. Even with the increase in foliar manganese amount, there was no increasing in soybean productivity. This shows that in soils with Mn levels above of the sufficient, it is not necessary foliar manganese addition in genetically modified soybean tolerant to glyphosate.

Key words: plant height, leaf concentration manganese, soybean productivity.

\section{INTRODUÇÃO}

O manganês (Mn) é um elemento essencial na nutrição de plantas e desempenha importantes funções, entre elas, a participação na fotossíntese, no metabolismo do nitrogênio, bem como, precursor de aminoácidos aromáticos, hormonais (auxinas), fenóis e ligninas (HEENAN \& CAMPBELL, 1980). Entretanto, a função mais bem definida do manganês é a da reação fotossintética na qual o oxigênio é produzido a partir da água.

O glyphosate é um potente herbicida de pósemergência, largo espectro e não seletivo (YAMADA \& CASTRO, 2007). Na soja Roundup Ready, o glyphosate é aplicado em pós-emergência durante a fase vegetativa da cultura, absorvido e translocado nas plantas, promovendo eficiente controle das plantas daninhas em um estádio em que essa competição seria extremamente prejudicial à cultura comercial. Embora o glyphosate seja eficiente no controle de plantas daninhas, existem relatos por parte de alguns pesquisadores dos diferentes efeitos fisiológicos induzidos por esse herbicida (LYDON \& DUKE, 1989).

A soja tolerante ao glyphosate pode sofrer injúrias ocasionadas pelo herbicida, sob determinadas condições e formulações do sal de glyphosate (REDDY \& ZABLATOWING, 2003). No trabalho desenvolvido por KRAUSZ \& YOUNG (2001), o glyphosate causou clorose mais acentuada nas folhas, quando aplicado no início do florescimento da soja (estádio R1), e isso foi intensificado com o aumento das doses utilizadas. Alguns autores têm relatado que o gene adicionado à soja tolerante ao herbicida glyphosate, pode ter alterado alguns processos fisiológicos da planta, retardando a absorção e a translocação do manganês, o que exigiria uma adição suplementar desse micronutriente, para evitar possível deficiência e comprometimento da produtividade da soja (GORDON, 2007). Mesmo reduzindo o conteúdo de clorofila, a biomassa de nódulos e o conteúdo de legmoglobina (REDDY et al., 2000), a maioria dos trabalhos realizados comprovaram ausência de efeito significativo desses fatores sobre a produtividade de grãos em soja tolerante ao glyphosate (CORREIA \& DURIGAN, 2007; CORREIA et al., 2008).
Em nível de campo, é perceptível visualmente certo amarelecimento da soja tolerante ao glyphosate após aplicação desse herbicida e muitos produtores e técnicos estão associando esse sintoma visual a uma possível deficiência de Mn. Por isso, com base na hipótese de que a soja tolerante ao glyphosate necessita da adição suplementar de manganês foliar devido a alterações na absorção e no metabolismo desse elemento, o presente trabalho teve por objetivo avaliar a resposta à aplicação foliar de $\mathrm{Mn}$ em soja transgênica tolerante ao glyphosate.

\section{MATERIAL E MÉTODOS}

Foram desenvolvidos dois experimentos no ano agrícola 2009/10, sendo o primeiro conduzido no município de Taquaruçú do Sul, RS, onde o solo apresentava as seguintes características químicas: $\mathrm{pH}$ em água(1:1) 5,7, índice SMP 6,2, argila 450 $\mathrm{g} \mathrm{kg}^{-1}$, matéria orgânica $240 \mathrm{~g} \mathrm{~kg}^{-1}$, potássio, cálcio, magnésio e alumínio $0,17,10,1,3,0 \mathrm{e} 0 \mathrm{cmol}_{\mathrm{c}} \mathrm{dm}^{-3}$, respectivamente. P-mehlich, enxofre e Mn com 2,2 e 12,0 e 27 $\mathrm{mg} \mathrm{dm}^{-3}$, respectivamente. $\mathrm{O}$ segundo experimento foi conduzido no município de Boa Vista das Missões, RS, onde o solo apresentava as seguintes características químicas: pH em água(1:1) 5,5, índice SMP 6,5, argila $650 \mathrm{~g} \mathrm{~kg}^{-1}$, matéria orgânica $380 \mathrm{~g} \mathrm{~kg}^{-1}$, potássio, cálcio, magnésio e alumínio $0,53,6,2,2,4 \mathrm{e} 0 \mathrm{cmol}_{\mathrm{c}} \mathrm{dm}^{-3}$, respectivamente. P-mehlich, enxofre e Mn com 8,4, 10,6 e 39 $\mathrm{m} \mathrm{dm}^{-3}$, respectivamente. Para ambos os locais, o teor de manganês no solo é considerado alto segundo recomendação da CQFS-RS/SC (2004).

A semeadura das cultivares de soja 'BMX Magna' e 'Fundacep 53' para Taquaruçú do Sul e Boa Vista das Missões, respectivamente, foi feita no dia 07/ $12 / 2009$ com equipamento tratorizado. O espaçamento utilizado foi de $0,45 \mathrm{~m}$ entre linhas em ambos os locais e uma densidade de 12 sementes viáveis por metro linear, o que corresponde a uma população de 266.000 plantas ha ${ }^{-1}$. A adubação de base por ocasião da semeadura foi realizada com aplicação de $230 \mathrm{~kg} \mathrm{ha}^{-1}$ da formulação 00-20-20.

Foram avaliados sete tratamentos: 1) sem aplicação de glyphosate, com controle manual das plantas daninhas e sem aplicação foliar de manganês (testemunha); 2) sem aplicação de glyphosate, com controle manual das plantas daninhas e uma aplicação foliar de manganês 7 dias após esse controle manual das plantas daninhas; 3) com aplicação de glyphosate 
e sem aplicação foliar de manganês; 4) aplicação de glyphosate em mistura com manganês; 5) aplicação de glyphosate mais uma aplicação foliar de manganês sete dias após aplicação do glyphosate; 6) aplicação de glyphosate mais aplicação foliar de manganês parcelada em duas épocas, aos 7 e 14 dias após aplicação do glyphosate; 7) aplicação de glyphosate e uma aplicação foliar de manganês aos 14 dias após aplicação de glyphosate. O delineamento experimental foi de blocos ao acaso com quatro repetições e cada parcela medindo $4,5 \times 5,0 \mathrm{~m}$.

Como fonte de Mn, foi utilizado o produto comercial Profol (Produquímica) com 14\% (m/v) de manganês solúvel na sua formulação e uma densidade de $1,36 \mathrm{~g} \mathrm{~mL}^{-1}$. Para todos os tratamentos que receberam aplicação foliar de $\mathrm{Mn}$, a dose utilizada foi 2,0 $\mathrm{L} \mathrm{ha}^{-1} \mathrm{do}$ produto comercial. A única aplicação de glyphosate para o manejo de plantas daninhas foi feita no estádio V5 da soja na dose de 2,0L ha ${ }^{-1}\left(360 \mathrm{~g}_{\text {e }} \mathrm{a} \mathrm{L}^{-1}\right)$ glyphosate. Nos tratamentos sem aplicação do glyphosate ( 1 e 2), o controle das invasoras foi feito com arranquio manual. Para o controle de pragas e doenças, o manejo seguiu o recomendado para a cultura da soja.

No pleno florescimento (estádio R.2), foi feita amostragem de folha para avaliação das concentrações de manganês $(\mathrm{Mn})$ e nitrogênio $(\mathrm{N})$. Para isso, foi coletado o quarto trifólio com pecíolo a partir do ápice da haste principal em 40 plantas aleatoriamente em cada parcela (EMBRAPA 2006). Essas amostras foram secas em estufa, moídas em moinho Willey para posterior determinação da concentração de $\mathrm{N}$ e $\mathrm{Mn}$, seguindo metodologia descrita por TEDESCO et al. (1995) para ambos os elementos.

Por ocasião da colheita, foram avaliadas as seguintes variáveis respostas: estatura de planta que representa a distância em centímetros a partir da superfície do solo até a extremidade do caule principal de 10 plantas aleatórias dentro da parcela útil. Altura de inserção da primeira vagem que representa a medida a partir da superfície do solo até a inserção da primeira vagem da haste principal em 10 plantas da área útil. Produtividade final de grãos em $\mathrm{kg} \mathrm{ha}^{-1}$, corrigida para $13 \%$ de umidade. Para a avaliação da produtividade, foi efetuado o arranquio manual das seis linhas centrais da área útil de cada parcela, sendo a trilha realizada com equipamento tratorizado estacionário.

Os dados foram submetidos à análise da variância e as médias comparadas pelo teste de Tukey a $5 \%$ de probabilidade.

\section{RESULTADOS E DISCUSSÃO}

Não houve efeito da aplicação do glyphosate sobre as concentrações de manganês no tecido foliar da soja (Tabela 1), corroborando com os dados apresentados em outros trabalhos (BOTT et al., 2008; CORREIA \& DURIGAN, 2009). As concentrações encontradas neste estudo estão acima das consideradas como críticas para o aparecimento dos sintomas de

Tabela 1 - Concentração foliar de manganês no pleno florescimento da soja nos experimentos conduzidos em Boa Vista das Missões e Taquaruçú do Sul. CESNORS/UFSM, Frederico Westphalen, RS, 2009/10.

\begin{tabular}{|c|c|c|c|c|c|c|}
\hline \multicolumn{3}{|c|}{ Tratamentos/aplicação } & \multicolumn{2}{|c|}{ Boa Vista das Missões - RS } & \multicolumn{2}{|c|}{ Taquaruçú do Sul - RS } \\
\hline Trat. & Glyphosate $^{(1)}$ & Manganês & ------------------- & ---- $\mathrm{mg} \mathrm{kg}^{-1}$ & seca ----------- & 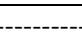 \\
\hline 1 & Sem & Sem & 135,87 & $\mathrm{~cd}^{(*)}$ & 229,77 & $\mathrm{c}$ \\
\hline 2 & Sem & $\operatorname{Com}^{(2)}$ & 312,60 & bcd & 1015,95 & a \\
\hline 3 & Com & Sem & 133,37 & $\mathrm{~d}$ & 240,00 & c \\
\hline 4 & Com & $\operatorname{Com}^{(3)}$ & 135,90 & $\mathrm{~cd}$ & 226,40 & $\mathrm{c}$ \\
\hline 5 & Com & $\operatorname{Com}^{(4)}$ & 338,05 & abc & 506,47 & $\mathrm{cb}$ \\
\hline 6 & Com & $\operatorname{Com}^{(5)}$ & 517,57 & $\mathrm{a}$ & 1011,70 & $\mathrm{a}$ \\
\hline 7 & Com & $\operatorname{Com}^{(6)}$ & 362,85 & $a b$ & 890,25 & $\mathrm{ab}$ \\
\hline \multicolumn{3}{|c|}{ Coeficiente de variação - \% } & \multicolumn{2}{|c|}{15,26} & \multicolumn{2}{|l|}{17,77} \\
\hline
\end{tabular}

\footnotetext{
${ }^{(1)}$ A aplicação de glyphosate na soja foi realizada no estádio V5. ${ }^{(2)}$ Aplicação de manganês 7 após o controle manual das plantas daninhas. ${ }^{(3)}$ Aplicação de manganês na mistura com glyphosate. ${ }^{(4)}$ Aplicação de Manganês sete dias após aplicação do glyphosate. ${ }^{(5)}$ Aplicação de manganês em duas épocas 7 e 14 dias após aplicação do glyphosate. ${ }^{(6)}$ Aplicação de manganês 14 dias após aplicação do glyphosate. ${ }^{(*)}$ Médias seguidas da mesma letra não diferem entre si pelo teste de Tukey a $5 \%$ de probabilidade.
} 
deficiência. Mesmo sem aplicação foliar de manganês, as concentrações observadas são consideradas altas, quando comparadas às concentrações de $100 \mathrm{a} 250 \mathrm{mg}$ $\mathrm{kg}^{-1}$ apontados com teores altos pela EMBRAPA (2006), o que se justifica pelo alto teor de manganês do solo para os dois locais de condução do experimento, segundo interpretação da Comissão de Química e Fertilidade de solo para os Estados do Rio Grande do Sul e Santa Catarina (CQFS-RS/SC, 2004).

A concentração de $\mathrm{Mn}$ foi menor nos tratamentos que não receberam aplicação foliar (1 e 3) e no tratamento 4, quando esse fertilizante foliar foi aplicado em mistura com glyphosate (Tabela1), prática usada por muitos produtores. A utilização de micronutriente em mistura com herbicidas como o glyphosate não tem sido recomendada pela comunidade científica, pois, além de não promover incremento a mistura pode reduzir a eficiência do próprio herbicida (BERNARDES et al., 2005). Para os demais tratamentos, a aplicação foliar de Mn aumentou as concentrações deste na folha, mostrando que o glyphosate não afetou a absorção e sua dinâmica na planta.

A concentração de nitrogênio no tecido foliar da soja foi semelhante entre os tratamentos estudados (Tabela2), ficando acima do adequado para a cultura da soja, conforme RAIJ et al. (1996). Segundo
BELLALOUI et al. (2008), mesmo com redução na assimilação de nitrogênio, o glyphosate não alterou a produtividade de grãos da soja transgênica. Para os autores, a aplicação de glyphosate nos estádios vegetativos e no início do ciclo reprodutivo da soja, quando a assimilação de nitrato é maior e menos sensível ao herbicida, pode explicar o efeito na assimilação de nitrogênio.

Os tratamentos não influenciaram significativamente na estatura de plantas e na altura de inserção da primeira vagem (Tabela 3). A ausência de efeito com a aplicação de glyphosate é semelhante aos resultados encontrados em soja sob diferentes doses comerciais do herbicida, já que não houve diferenças na estatura de plantas quando foram aplicadas as doses de zero até $1440 \mathrm{~g}$ i.a ha ${ }^{-1}$ (FILHO et al., 2010).

Quanto à produtividade, mesmo havendo diferença nos teores foliares entre os tratamentos com e sem aplicação de manganês (Tabela1), isso não se refletiu em aumento de produtividade da soja (Tabela 4). Resultados semelhantes foram observados por MOREIRA et al. (2006). A soja que foi geneticamente modificada pela adição de um gene que codifica a enzima EPSPS torna-se tolerante à ação do glyphosate e continua produzindo compostos essenciais ao seu desenvolvimento, seu crescimento, não sendo afetado pelos efeitos do herbicida (PADGETTE, 1995). Essa

Tabela 2 - Concentração foliar de nitrogênio no pleno florescimento da soja nos experimentos conduzidos em Boa Vista das Missões e Taquaruçú do Sul. CESNORS/UFSM, Frederico Westphalen, RS, 2009/10.

\begin{tabular}{|c|c|c|c|c|c|c|}
\hline \multicolumn{3}{|c|}{ Tratamentos/aplicação } & \multicolumn{2}{|c|}{ Boa Vista das Missões - RS } & \multicolumn{2}{|c|}{ Taquaruçú do Sul - RS } \\
\hline Trat. & Glyphosate $^{(1)}$ & Manganês & ----------------' & $\mathrm{mg} \mathrm{kg}^{-1}$ & ia seca -------- & ---------. \\
\hline 1 & Sem & Sem & 73,31 & $\mathrm{a}^{(*)}$ & 47,16 & $\mathrm{a}$ \\
\hline 2 & Sem & $\mathrm{Com}^{(2)}$ & 79,89 & $\mathrm{a}$ & 49,93 & a \\
\hline 3 & Com & Sem & 77,26 & a & 59,86 & a \\
\hline 4 & Com & $\operatorname{Com}^{(3)}$ & 76,26 & a & 58,96 & a \\
\hline 5 & Com & $\mathrm{Com}^{(4)}$ & 79,48 & $\mathrm{a}$ & 53,02 & a \\
\hline 6 & Com & $\operatorname{Com}^{(5)}$ & 73,40 & a & 56,19 & a \\
\hline 7 & Com & $\operatorname{Com}^{(6)}$ & 78,77 & $\mathrm{a}$ & 52,80 & a \\
\hline \multicolumn{3}{|c|}{ Coeficiente de variação - \% } & \multicolumn{2}{|c|}{2,54} & \multicolumn{2}{|c|}{8,75} \\
\hline
\end{tabular}

\footnotetext{
${ }^{(1)} \mathrm{A}$ aplicação de glyphosate na soja foi realizada no estádio V5. ${ }^{(2)}$ Aplicação de manganês 7 após o controle manual das plantas daninhas. ${ }^{(3)}$ Aplicação de manganês na mistura com glyphosate. ${ }^{(4)}$ Aplicação de Manganês sete dias após aplicação do glyphosate. ${ }^{(5)}$ Aplicação de manganês em duas épocas 7 e 14 dias após aplicação do glyphosate. ${ }^{(6)}$ Aplicação de manganês 14 dias após aplicação do glyphosate. ${ }^{(*)}$ Médias seguidas da mesma letra não diferem entre si pelo teste de Tukey a 5\% de probabilidade.
} 
Tabela 3 - Estatura de planta e altura de inserção da primeira vagem de soja nos experimentos conduzidos em Boa Vista das Missões e Taquaruçú do Sul. CESNORS/UFSM, Frederico Westphalen, RS, 2009/10.

\begin{tabular}{|c|c|c|c|c|c|c|c|c|c|c|}
\hline \multirow{4}{*}{$\begin{array}{c}\text { Trat. } \\
1\end{array}$} & \multirow{2}{*}{\multicolumn{2}{|c|}{ Tratamentos/aplicação }} & \multicolumn{4}{|c|}{--------Boa Vista das Missões - RS-------- } & \multicolumn{4}{|c|}{----------Taquaruçú do Sul - RS----------- } \\
\hline & & & \multicolumn{2}{|c|}{ Estatura de planta } & \multicolumn{2}{|c|}{$\begin{array}{l}\text { Altura de inserção } \\
\text { da } 1^{\underline{a}} \text { vagem }\end{array}$} & \multicolumn{2}{|c|}{ Estatura de planta } & \multicolumn{2}{|c|}{$\begin{array}{c}\text { Altura de inserção } \\
\text { da } 1^{\underline{\underline{a}}} \text { vagem }\end{array}$} \\
\hline & Glyphosate $^{(1)}$ & Manganês & \multicolumn{4}{|c|}{ 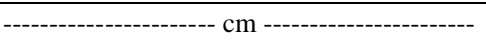 } & \multicolumn{4}{|c|}{ 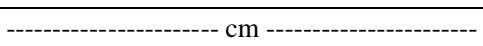 } \\
\hline & Sem & Sem & 65,5 & $a^{(*)}$ & 14,5 & $\mathrm{a}$ & 74,1 & $\mathrm{a}$ & 20,5 & a \\
\hline 2 & Sem & $\mathrm{Com}^{(2)}$ & 67,9 & a & 14,9 & $\mathrm{a}$ & 76,7 & $\mathrm{a}$ & 22,2 & $\mathrm{a}$ \\
\hline 3 & Com & Sem & 65,0 & $\mathrm{a}$ & 15,6 & $\mathrm{a}$ & 73,8 & $\mathrm{a}$ & 20,2 & $\mathrm{a}$ \\
\hline 4 & Com & $\mathrm{Com}^{(3)}$ & 66,4 & $\mathrm{a}$ & 16,1 & $\mathrm{a}$ & 72,5 & $\mathrm{a}$ & 20,4 & $\mathrm{a}$ \\
\hline 5 & Com & $\mathrm{Com}^{(4)}$ & 65,2 & $\mathrm{a}$ & 15,3 & $\mathrm{a}$ & 68,4 & $\mathrm{a}$ & 21,7 & $\mathrm{a}$ \\
\hline 6 & Com & $\mathrm{Com}^{(5)}$ & 64,8 & $\mathrm{a}$ & 14,5 & $\mathrm{a}$ & 72,6 & $\mathrm{a}$ & 21,7 & $\mathrm{a}$ \\
\hline 7 & Com & $\mathrm{Com}^{(6)}$ & 64,8 & $\mathrm{a}$ & 15,7 & a & 75,0 & $\mathrm{a}$ & 22,0 & $\mathrm{a}$ \\
\hline \multicolumn{3}{|c|}{ Coeficiente de variação - \% } & \multicolumn{2}{|c|}{1,79} & \multicolumn{2}{|c|}{4,74} & \multicolumn{2}{|c|}{5,69} & \multicolumn{2}{|c|}{3,05} \\
\hline
\end{tabular}

${ }^{(1)}$ A aplicação de glyphosate na soja foi realizada no estádio V5. ${ }^{(2)}$ Aplicação de manganês 7 após o controle manual das plantas daninhas. ${ }^{(3)}$ Aplicação de manganês na mistura com glyphosate. ${ }^{(4)}$ Aplicação de Manganês 7 dias após aplicação do glyphosate. ${ }^{(5)}$ Aplicação de manganês em duas épocas 7 e 14 dias após aplicação do glyphosate. ${ }^{(6)}$ Aplicação de manganês 14 dias após aplicação do glyphosate. ${ }^{(*)}$ Médias seguidas da mesma letra não diferem entre si pelo teste de Tukey a $5 \%$ de probabilidade.

clorose que aparece na soja após aplicação do glyphosate é mais acentuada quanto mais precoce for a aplicação e se intensifica à medida que ocorre um aumento na dose, conforme constatado por KRAUSZ \& YOUNG (2001). Nesse trabalho, os autores descrevem que esses sintomas permaneceram restritos às folhas que receberam o produto e as folhas novas apresentaram-se sem injúrias, não comprometendo a produtividade final. Isso mostra que, em solos com teores de Mn acima do suficiente, como o do presente estudo, não é necessária suplementação foliar de manganês em soja geneticamente modificada e tolerante ao glyphosate.

\section{CONCLUSÃO}

A aplicação de glyphosate na cultura da soja não afeta a absorção e os teores foliar de manganês e nitrogênio. $\mathrm{O}$ aumento do teor foliar de $\mathrm{Mn}$ não se reflete em aumentou da produtividade de soja.

Tabela 4 - Produtividade da soja em função de diferentes manejos de manganês foliar nos experimentos conduzidos em Boa Vista das Missões e Taquaruçú do Sul. Frederico Westphalen, RS, CESNORS/UFSM, 2009/10.

\begin{tabular}{|c|c|c|c|c|c|c|}
\hline \multicolumn{3}{|c|}{ Tratamentos/aplicação } & \multicolumn{2}{|c|}{ Boa Vista das Missões - RS } & \multicolumn{2}{|c|}{ Taquaruçú do Sul - RS } \\
\hline Trat. & Glyphosate $^{(1)}$ & Manganês & ------------------ & - & 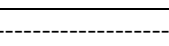 & 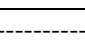 \\
\hline 1 & Sem & Sem & $3.217,7$ & $\mathrm{a}^{(*)}$ & $2.399,6$ & $\mathrm{a}$ \\
\hline 2 & Sem & $\mathrm{Com}^{(2)}$ & $3.265,9$ & $\mathrm{a}$ & $2.426,6$ & a \\
\hline 3 & Com & Sem & $3.337,8$ & $\mathrm{a}$ & $2.448,6$ & $\mathrm{a}$ \\
\hline 4 & Com & $\operatorname{Com}^{(3)}$ & $3.317,0$ & a & $2.469,6$ & a \\
\hline 5 & Com & $\operatorname{Com}^{(4)}$ & $3.290,3$ & a & $2.283,3$ & $\mathrm{a}$ \\
\hline 6 & Com & $\mathrm{Com}^{(5)}$ & $3.356,7$ & a & $2.401,9$ & $\mathrm{a}$ \\
\hline 7 & Com & $\operatorname{Com}^{(6)}$ & $3.205,7$ & $\mathrm{a}$ & $2.551,9$ & a \\
\hline \multicolumn{3}{|c|}{ Coeficiente de variação - \% } & \multicolumn{2}{|c|}{4,02} & \multicolumn{2}{|l|}{7,40} \\
\hline
\end{tabular}

\footnotetext{
${ }^{(1)}$ A aplicação de glyphosate na soja foi realizada no estádio V5. ${ }^{(2)}$ Aplicação de manganês 7 após o controle manual das plantas daninhas. ${ }^{(3)}$ Aplicação de manganês na mistura com glyphosate. ${ }^{(4)}$ Aplicação de Manganês sete dias após aplicação do glyphosate. ${ }^{(5)}$ Aplicação de manganês em duas épocas 7 e 14 dias após aplicação do glyphosate. ${ }^{(6)}$ Aplicação de manganês 14 dias após aplicação do glyphosate.

${ }^{(*)}$ Médias seguidas da mesma letra não diferem entre si pelo teste de Tukey a 5\% de probabilidade.
} 


\section{REFERÊNCIAS}

BELLALOUI, N. et al. Nitrogen metabolism and seed composition as influenced by glyphosate application in glyphosate-resistant soybean. Journal of Agricultural and Food Chemistry, v.56, p.2765-2772, 2008. Disponível em: <http://pubs.acs.org/doi/pdf/10.1021/jf703615m>. Acesso em: 14 out. 2009 . doi: $10.1021 / \mathrm{jf} 703615 \mathrm{~m}$.

BERNARDES, M.L.; THELEN, K.D. Glyphosate interaction with manganese in tank mixtures and its effect on glyphosate absorption and translocation. Weed Science, v.53, p.787794, 2005. Disponível em: <http://www.bioone.org/doi/full/ 10.1614/WS-05-043R.1>. Acesso em: 27 ago. 2009. doi: 10.1614/WS-05-043R.1.

BOTT, S. et al. Glyphosate-induced impairment of plant growth and micronutrient status in glyphosate-resistant soybean (Glycine max L.). Plant and Soil, v.312, p.185-194, 2008. Disponível em: <http://www.springerlink.com/content/ c41002503810711p/fulltext.pdf>. Acesso em: $24 \mathrm{dez} .2009$. doi 10.1007/s11104-008-9760-8.

COMISSÃO DE QUÍMICA E FERTILIDADE DO SOLO (CQFS $\mathrm{RS} / \mathrm{SC}$ ). Manual de adubação e calagem para os estados do Rio Grande do Sul e Santa Catarina. 10.ed. Porto Alegre: Sociedade Brasileira de Ciência do Solo/Núcleo Regional Sul, 2004. 400p.

CORREIA, N.M.; DURIGAN, J.C. Seletividade de diferentes herbicidas à base de glyphosate a soja RR. Planta Daninha, v.25, p.375-379, 2007. Disponível em: <http://www.scielo.br/ pdf/pd/v25n2/a18v25n2.pdf>. Acesso em: 19 out. 2009. doi $10.1590 / \mathrm{S} 0100-83582007000200018$.

CORREIA, N.M.; DURIGAN, J.C. et al. Seletividade da soja transgênica tolerante ao glyphosate e eficácia de controle de Commelina benghalensis com herbicidas aplicados isolados e em misturas. Bragantia, v.67, p.563-568, 2008.

CORREIA, N.Z.; DURIGAN, J.C. Glyphosate e adubação foliar com manganês na cultura da soja transgênica. Planta Daninha, v.27, p.721-727, 2009. Disponível em: <http://www.scielo.br/ $\mathrm{pdf} / \mathrm{pd} / \mathrm{v} 27 \mathrm{n} 4 / 10 . \mathrm{pdf}>$. Acesso em: 25 set. 2009. doi: 10.1590/ S0100-83582009000400010.

EMPRESA BRASILEIRA DE PESQUISA AGROPECUÁRIA EMBRAPA. Tecnologias de produção de soja - região central do Brasil - 2007. Londrina: Embrapa Soja, Embrapa Cerrados, Embrapa Agropecuária Oeste, 2006. 225p. (Sistemas de Produção).

FILHO, A.L.M. et al. Efeito de glyphosate sobre características produtivas em cultivares de soja transgênica e convencional. Biosciense Journal v.26, p. 322-333, 2010.
GORDON, B. Adubação com manganês em soja convencional e soja resistente ao glifosato. Informações Agronômicas, n.177, p.6-7, 2007.

HEENAN, D.P.; CAMPBELL, L.C. Soybean nitrate reductase activity influenced by manganese nutrition. Plant Cell Physiolgy, v.21, p.731-736, 1980.

KRAUSZ, R.E.; YOUNG, B.G. Response of glyphosate resistant soybean (Glycine $\max$ ) to trimethylsulfonium and isopropylamine salts of glyphosate. Weed Technolgy, v.15, p.745-749, 2001. Disponível em: <http://www.bioone.org/doi/full/10.1614/0890037X\%282001\%29015\%5B0745\%3AROGRSG\%5D2.0.CO\%3B2>. Acesso em: 12 set. 2009. doi: 10.1614/0890037X(2001)015[0745:ROGRSG]2.0.CO;2.

LYDON, J.; DUKE, S.O. Pesticide effects on secondary metabolism of higher plants. Pesticide Science, v.25, p.361373, 1989.

MOREIRA, S.G. et al. Formas químicas, disponibilidade de manganês e produtividade de soja em solos sob semeadura direta. Revista Brasileira de Ciência do Solo, v.30, p.121-136, 2006.

PADGETTE, S.R. et al. Development, Identification, and Characterization of a Glyphosate- Tolerant Soybean Line. Crop Science, v.35, p.1451-1461, 1995.

RAIJ, B. van.; CANTARELLA, H. Recomendações de adubação e calagem para o estado de São Paulo. Campinas: instituto Agronômico, 1996. 285p. (IAC. Boletim Técnico, $100)$.

REDDY, K.N. et al. Effect of glyphosate on growth, chlorophyll, and nodulation in glyphosate-resistant and susceptible soybean (Glycine max) varieties. Journal New Seeds, v.2, p.37-52, 2000. Disponível em: <http://www.informaworld.com/smpp/ content $\sim \mathrm{db}=$ all $\sim$ content $=\mathrm{a} 903885519>$. Acesso em: 21 jul.2009. doi: $10.1300 / \mathrm{J} 153 \mathrm{v} 02 \mathrm{n} 03 \_03$.

REDDY, N.K.; ZABLOTOWICZ, R.M. Glyphosate-resistant soybean response to various salts of glyphosate and glyphosate accumulation in soybean nodules. Weed Science, v.51, n.4, p.496-502, 2003. Disponível em: <http://www.bioone.org/doi/full/10.1614/0043$1745 \% 282003 \% 29051 \% 5 \mathrm{~B} 0496 \% 3$ AGSRTVS\%5D2.0.CO\%3B2>. Acesso em: 24 nov. 2009. doi: 10.1614/00431745(2003)051 [0496:GSRTVS]2.0.CO;2.

TEDESCO, M.J. et al. Análise de solo, plantas e outros materiais. Porto Alegre: Universidade Federal do Rio Grande do Sul, 1995. $174 \mathrm{p}$.

YAMADA, T.; CASTRO, P.R.C. Efeito do glifosato nas plantas: implicações fisiológicas e agronômicas. Encarte técnico. Informações Agronômicas, n.119, 32p, 2007. 